\title{
Peningkatan Kualitas Gula Semut Melalui Introduksi Alat Pengering bagi Kelompok Pengrajin Gula Aren di Desa Kekait Kabupaten Lombok Barat
}

\author{
Hary Kurniawan ${ }^{1}$, Fakhrul Irfan Khalil ${ }^{2}$, Kiki Rizqia Septiyana ${ }^{3}$, Muhammad Adnand ${ }^{4}$, \\ Imam Adriansyah ${ }^{5}$, Hasmi Nurkayanti ${ }^{6}$, \\ 1,2,3,4,5,6 Universitas Mataram afiliasi \\ harykurniawan@unram.ac.id
}

\begin{abstract}
Abstrak
Program pengabdian masyarakat berupa pelatihan peningkatan kualitas gula semut melalui introduksi alat pengering pada kelompok pengrajin gula aren di Desa Kekait, Kecamatan Gunungsari, Kabupaten Lombok Barat telah dilaksanakan. Sasaran dari kegiatan ini adalah pengrajin gula aren yang tergabung dalam UKM Maju Bersama. Tujuan dari kegiatan ini yaitu meningkatkan kualitas gula semut melalui introduksi alat pengering silinder tipe rak pada kelompok usaha pengrajin gula semut UKM Maju Bersama. Pelatihan mengenai cara pengolahan pangan yang baik dan pengenalan alat pengering dilakukan untuk meningkatkan pengalaman dan keterampilan peserta. Pelatihan pengolahan pangan yang baik memberikan dampak positif bagi peserta, terutama meningkatnya kesadaran peserta dalam menangani produk pangan selama produksi sehingga produk layak dan aman dikonsumsi saat berada di tangan konsumen. Peserta juga dikenalkan dengan teknologi tepat guna berupa alat pengering dan dilatih cara pengoperasian dan perawatan alat pengering gula semut dan sebagai hasilnya keterampilan mitra dalam mengoperasikan alat dan mengeringkan gula semut meningkat. Hasil pengujian kadar air menunjukkan bahwa sebelum dikeringkan kadar air gula semut yang dihasilkan mitra adalah 5,20\%. Setelah pengeringan selama 3 jam, diperoleh kadar air akhir sebesar 2,49\% dimana kadar air tersebut telah memenuhi SNI Gula Palma.
\end{abstract}

Kata Kunci: Alat pengering, Gula aren, Gula semut

\section{Pendahuluan}

Desa Kekait yang berada di Kecamatan Gunung Sari, Kabupaten Lombok merupakan salah satu desa yang banyak ditumbuhi tanaman aren. Sebagian besar masyarakat setempat telah memanfaatkan nira aren menjadi berbagai olahan dan sekaligus bermata pencaharian sebagai pengrajin gula aren. Salah satu produk unggulan di Desa Kekait yaitu gula semut aren yang diproduksi oleh kelompok usaha "Maju Bersama". Gula semut memiliki beberapa keunggulan diantaranya mudah diaplikasikan sebagai bahan tambahan makanan maupun minuman, lebih praktis dalam pengemasan, penyimpanan dan pendistribusian, serta memiliki umur simpan yang lebih panjang (Amanah et al., 2013; Fahrizal, et al., 2017; Kurniawan et al., 2018; Septiyana et al., 2019). Bahkan Joseph dan Layuk (2012) melaporkan bahwa upaya 


\section{Jcommdev}

JCommdev- JOURNAL OF COMMUNITY DEVELOPMENT \& EMPOWERMENT

meningkatkan nilai jual gula aren yang lembek dilakuan dengan cara mengolah menjadi gula aren granular (gula semut), melalui peleburan kembali gula cetak dengan penambahan air menjadi larutan gula, kemudian dimasak menjadi granular (serbuk).

Kelompok usaha "Maju Bersama" telah terbentuk sejak tahun 2016 dengan kapasitas produksi gula semut yang dihasilkan sebesar 2 - $5 \mathrm{~kg}$ per hari dan dijual dengan harga Rp. 25.000 per 250 gram. Namun selama ini gula semut masih dikeringkan melalui penjemuran dibawah sinar matahari yang artinya sangat bergantung pada kondisi cuaca. Selain itu resiko kontaminasi terhadap produk cukup tinggi dan sulit dikontrol selama penjemuran berlangsung. Gula semut yang dihasilkan kadar airnya masih tinggi yaitu $5-7 \%$. Sementara itu, berdasarkan SNI Gula Palma, kadar air gula semut maksimum sebesar 3\%. Ritonga et al., (2020) melaporkan bahwa gula semut merupakan produk yang diduga mempunyai umur simpan yang pendek. Kadar air dan akitifitas air yang tinggi akan menyebabkan gula semut susah dipisahkan. Kadar air gula semut yang tinggi akan memicu terjadinya penggumpalan gula (clumping), hal ini juga akan mengurangi kualitas fisik produk. Mutu produk yang rendah berakibat penurunan umur simpan produk yang sangat cepat. Oleh karena itu apabila tidak dikeringkan, gula semut mudah rusak dan memiliki umur simpan yang pendek. Selain itu gula semut bersifat higroskopis sehingga mudah menyerap uap air dari udara sekitar, akibatnya gula semut tidak tahan lama (Dewi, 2018; Kurniawan et al., 2018; Septiyana et al., 2019; Attahmid et al., 2019).

Pengeringan merupakan salah satu cara mengeluarkan sebagian air dari suatu bahan dengan cara menguapkan air dari dalam bahan tersebut. Selama proses pengeringan terjadi 2 peristiwa penting yaitu perpindahan panas dan perpindaha massa yang terjadi secara simultan. Pada pengeringan, kecepatan perpindahan panas dari udara pengering dipengaruhi oleh tipe alat pengering yang digunakan, bahan konstruksi yang digunakan, metode pengeringan, kecepatan tekanan dan suhu udara pengering dan suhu permukaan bahan (Amanah et al., 2013; Septiyana et al., 2019).

Dalam proses produksi gula semut, pengeringan merupakan tahapan yang sangat penting karena membantu menurunkan kadar air gula semut dari $7 \%$ sampai $3 \%$ sehingga aman untuk disimpan dalam waktu yang lama. Kadar air akhir yang diperoleh menunjukkan bahwa pengeringan dengan alat pengering mampu menguapkan air dari produk lebih banyak dibandingkan dengan pengeringan matahari (Amanah et al., 2013).

Gula aren, terutama gula semut merupakan salah satu produk yang memiliki nilai ekonomis yang tinggi dan memiliki prospek yang sangat bagus untuk dikembangkan. Hal ini disebabkan kencenderungan permintaan yang terus meningkat guna memenuhi kebutuhan ekspor maupun kebutuhan dalam negeri.

Permintaan untuk produk ini terus meningkat. Sampai saat ini sebagian besar produksi gula aren masih diserap pasar dalam negeri, sementara itu untuk permintaan dari luar negeri belum dapat dipenuhi karena keterbatasan produksi. Kendala utama produk gula aren, terutama gula semut, untuk ekspor adalah rendahnya kualitas yang dihasilkan dan umumnya belum memenuhi standar mutu yang disyaratkan serta ditinjau dari segi kebersihan, bentuk, 


\section{Jcommdev}

JCommdev- JOURNAL OF COMMUNITY DEVELOPMENT \& EMPOWERMENT

ukuran, sifat fisik dan kimia produk yang dihasilkan belum seragam (Evalia, 2015; Musita, 2019). Oleh karen itu tujuan dari kegiatan pengabdian ini yaitu meningkatkan kualitas gula semut melaui introduksi alat pengering silinder tipe rak pada kelompok usaha pengrajin gula semut Maju Bersama.

\section{Metode}

Sasaran dari kegiatan ini adalah pengrajin gula semut yang tergabung dalam kelompok usaha Maju Bersama yang berlokasi di Desa Kekait, Kecamatan Gunung Sari, Kabupaten Lombok Barat. Metode yang digunakan yaitu pelatihan. Pendekatan ini dilakukan guna meningkatkan pengetahuan dan keterampilan melalui penyuluhan, demonstrasi dan diskusi. Kegiatan ini melalui beberapa tahap, mulai tahap persiapan, pengurusan administrasi dan surat menyurat, tahap pertemuan awal kelompok sasaran, pelatihan dan demonstrasi. Adapun rangkaian kegiatan ini meliputi 1) penyuluhan mengenai Cara Pengolahan Pangan yang Baik (CPPB) guna meningkatkan pemahaman mitra pentingnya kebersihan dan higienitas mulai dari penanganan bahan baku, proses produksi hingga produk jadi, dan 2) pelatihan pengeringan gula semut menggunakan alat pengering silinder tipe rak. Evaluasi yang diterapkan dalam kegiatan ini berupa forum group discussion serta evaluasi pada produk setelah dikeringkan. Penyampaian materi disajikan dalam bentuk leaflet dan poster. Sementara itu peralatan yang digunakan dalam kegiatan ini antara lain unit pengering, thermometer digital, oven, timbangan, cawan dan penjepit. Gula semut yang diproduksi oleh mitra diukur kadar air air sebelum dan setelah dikeringkan menggunakan metode oven.

\section{Hasil dan Output}

\section{Penyuluhan Cara Pengolahan Pangan yang Baik (CPPB)}

Berdasarkan Keputusan Kepala BPOM RI tahun 2003, cara pengolahan pangan yang baik (CPPB) merupakan salah satu faktor yang penting untuk memenuhi standar mutu atau persyaratan yang ditetapkan untuk pangan. CPPB sangat berguna bagi kelangsungan hidup industri pangan baik yang berskala kecil, sedang, maupun yang bersakla besar. Melalui CPPB ini, industri pangan dapat menghasilkan pangan yang bermutu, layak dkonsumsi dan aman bagi kesehatan. Dengan menghasilkan pangan yang bermutu dan aman untuk dikonsumsi, kepercayaan masyarakat niscaya akan meningkat, dan industri pangan yang bersangkutan akan berkembang pesat. Dengan berkembangnya industri pangan yang menghasilkan pangan yang bermutu dan aman untuk dkonsumsi, maka masyarakat pada umumnya akan terlindung dari penyimpangan mutu pangan dan bahaya yang mengancam kesehatan.

Dalam kegiatan ini, para pengrajin gula semut yang tergabung dalam UKM Maju Bersama diberikan penyuluhan mengenai cara pengolahan pangan yang baik agar dapat memenuhi berbagai persyaratan produksi yang baik seperti persyaratan lokasi, bangunan dan fasilitas, peralatan produksi, pengendalian hama, higiene karyawan, pengendalian proses dan pengawasan. Penyuluhan disampaikan melalui ceramah yang dibantu dengan alat peraga seperti leaflet dan poster. Selain itu peserta juga diberikan pelatihan cara menggunakan perlengkapan standar pengolahan seperti apron, penutup kepala, masker dan sarung tangan. 


\section{Jcommdev}

JCOmmdev- JOURNAL OF COMMUNITY DEVELOPMENT \& EMPOWERMENT

E-ISSN : 2723-4398

Selama kegiatan berlangsung, dilakukan diskusi maupun tanya jawab terkait cara pengolahan pangan yang baik. Peserta cukup antusias mengikuti penyuluhan ini yang ditandaian dengan diskusi dan tanya jawab. Hasil kegiatan ditunjukkan pada Gambar 1.
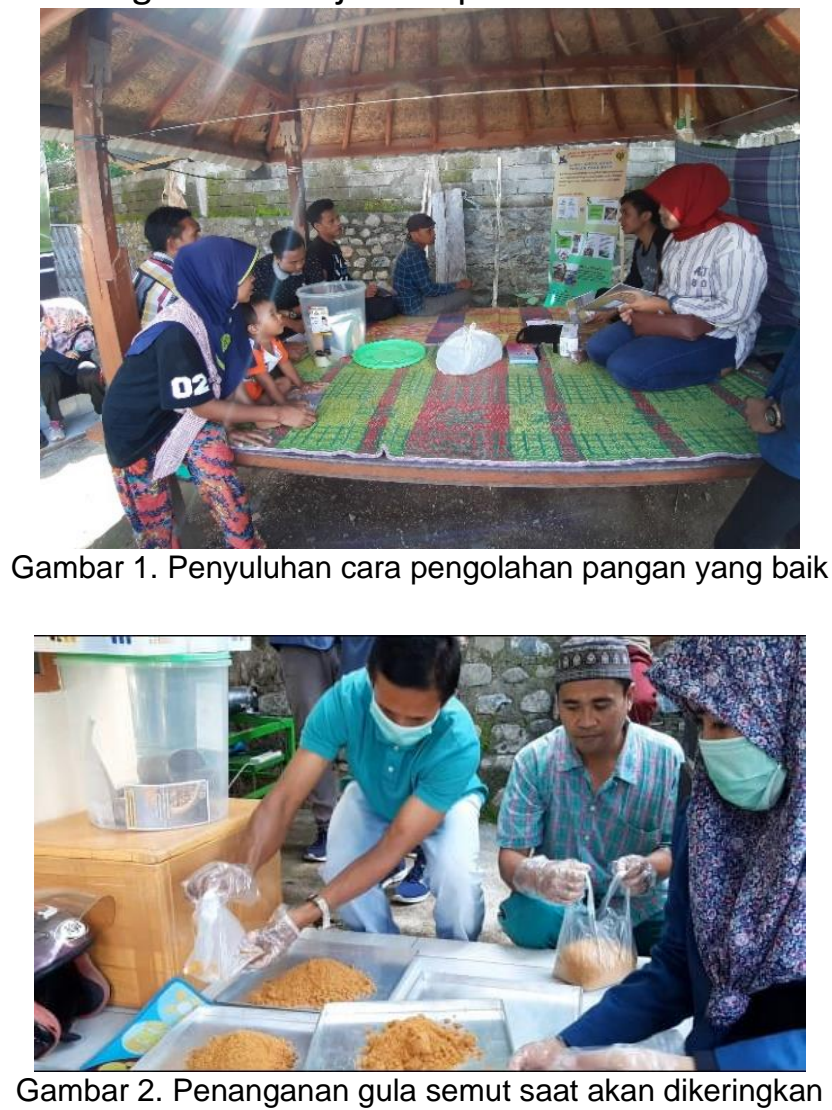

\section{Introduksi Alat Pengering Silinder Tipe Rak}

Selain diberikan penyuluhan mengenai cara pengolahan pangan yang baik, peserta juga diintroduksi teknologi tepat guna berupa alat pengering gula semut. Alat pengering berbentuk silinder berdiameter $600 \mathrm{~mm}$ dengan dimensi $1200 \mathrm{~mm}$ x $750 \mathrm{~mm} \times 2150 \mathrm{~mm}$ yang terdiri dari 8 rak dengan ukuran loyang $340 \mathrm{~mm} \times 340 \mathrm{~mm}$ dan sumber pemanas berasal dari kompor gas.

Introduksi alat pengering gula semut dilakukan dengan praktek cara pengoperasian alat pengering serta praktek mengeringkan gula semut seperti yang ditunjukkan pada Gambar 3. Berdasarkan hasil kegiatan yang dilakukan, peserta dapat mengoperasikan alat pengering dan dapat mempraktekan cara mengeringkan gula semut dari kadar air $5 \%$ menjadi $3 \%$. Selain itu, pemahaman mitra mengenai pentingnya pengeringan gula semut semakin meningkat setelah ditunjukkan perbedaan antara gula semut yang dikeringkan dengan yang tidak dikeringkan. 


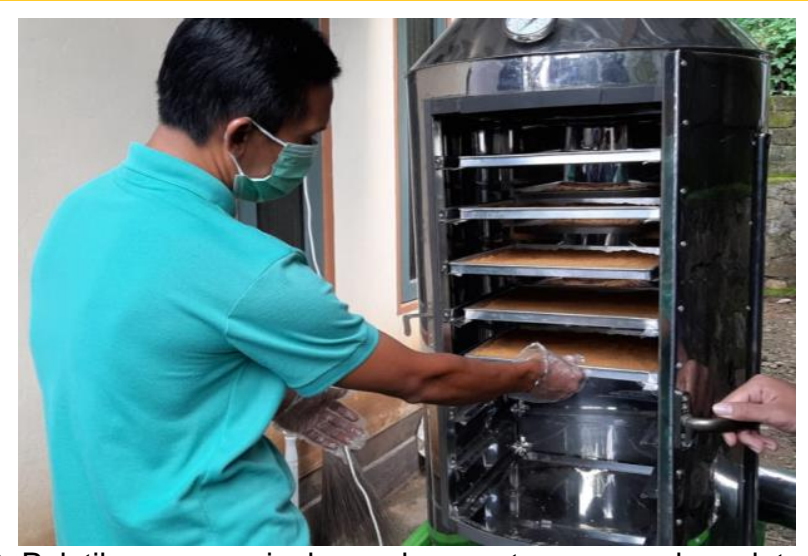

Gambar 3. Pelatihan mengeringkan gula semut menggunakan alat pengering

Pengeringan produk pangan telah banyak diterapkan industri saat ini. Pengeringan sendiri merupakan salah satu teknologi pengolahan pangan yang dilakukan dengan cara mengeluarkan sebagian air dari suatu bahan dengan cara menguapkan air dari dalam bahan tersebut. Oleh karena itu sasaran pengeringan adalah menurunkan kadar air atau aktivitas air (aw), menghambat pertumbuhan bakteri, menurunkan aktivitas enzim, serta menurunkan laju perubahan kimia yang tidak diinginkan sehingga akan membuat produk dapat disimpan lebih lama dengan mutu yang lebih terjaga. Selain itu pengeringan dapat menurunkan biaya dan memudahkan dalam proses penyimpanan, pengemasan dan pengangkutan. Pengeringan bertujuan untuk memperpanjang umur simpan produk (Ummah et al., 2016; Sushanti \& Sirwanti, 2018; Amanah et al., 2013)

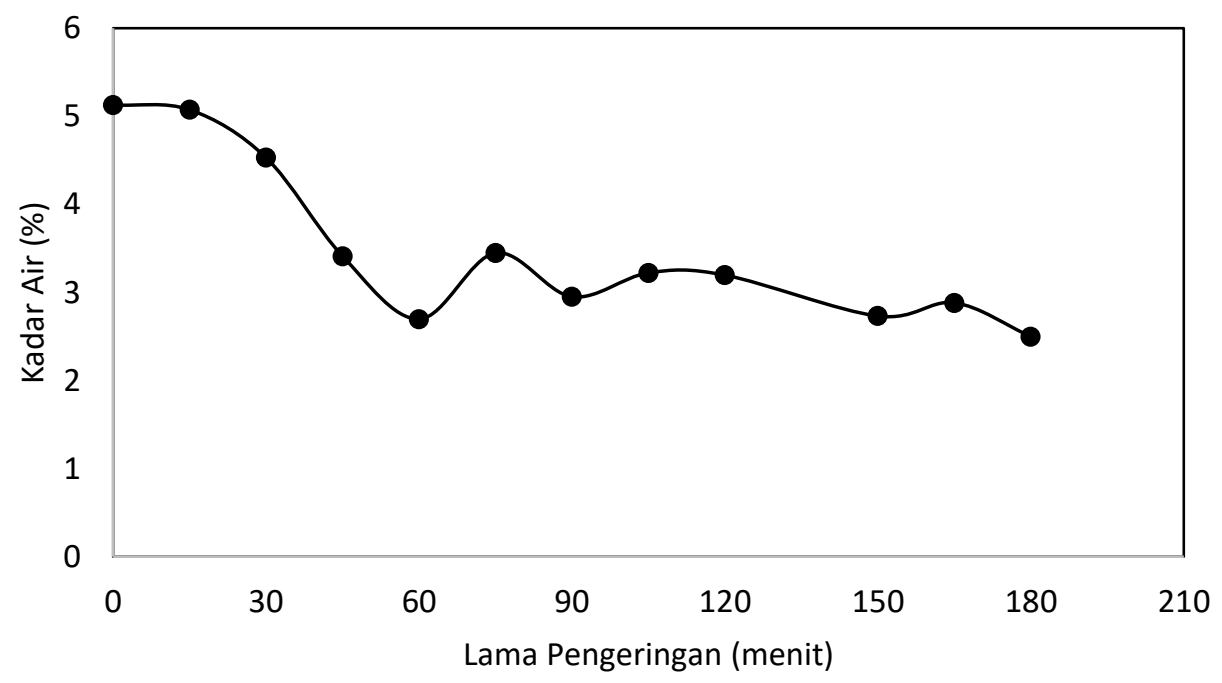

Gambar 4. Perubahan kadar air gula semut selama pengeringan menggunakan alat pengering

Selama pengeringan menggunakan alat pengering silinder tipe rak, kadar air gula semut mengalami penurunan seperti yang ditunjukkan pada gambar 4. Proses pengeringan dipengaruhi oleh kondisi udara pengering, sifat internal bahan dan sistem pengeringan yang diterapkan. Pada proses pengeringan perpindahan panas dan uap air secara simultan, JCommdev Vol 1, No. 2, 2020, hlm. 88 - 95 
memerlukan energi panas untuk menguapkan kandungan air yang dipindahkan dari permukaan bahan yang dikeringkan oleh media pengering yang biasanya berupa panas (Ummah et al., 2016; Sushanti \& Sirwanti, 2018; Amanah et al., 2013). Hasil pengukuran diperoleh suhu udara dalam ruang pengering rata-rata sebesar $51,50^{\circ} \mathrm{C}$. Lama pengeringan berlangsung selama 3 jam dan diperoleh kadar air akhir gula semut sebesar $2.49 \%$. Kadar air akhir ini telah memenuhi standa SNI Gula Palma yaitu maksimal sebesar 3\%.

\section{Simpulan dan Saran}

Pelatihan mengenai cara pengolahan pangan yang baik telah memberikan dampak positif kepada peserta terutama meningkatnya kesadaran peserta dalam menangani produk pangan selama produksi agar produk layak dan aman dikonsumsi saat berada ditangan Konsumen. Peserta juga diintroduksi teknologi tepat guna berupa alat pengering dan dilatih bagaimana cara mengoperasikan dan merawat alat pengering gula semut dan hasilnya keterampilan mitra dalam mengoperasikan dan mengeringkan gula semut juga meningkat. Hasil uji kadar air menunjukan bahwa sebelum dikeringkan kadar air gula semut yang dihasilkan oleh mitra sebesar 5,20\%. Namun setelah dikeringkan selama 3 jam, diperoleh kadar air akhir sebesar 2.49\% dimana kadar air ini telah memenuhi SNI Gula Palma.

\section{Daftar Pustaka}

Amanah, H.Z., T, Erlinda, Rahayoe, S., Setyowati, P. (2013). Analisis Kinerja Alat Pengering Tipe Rak (Cabinet Dryer) untuk Pengeringan Gula Semut. Seminar Nasional Sains \& Teknologi, Lembaga Penelitian Universitas Lampung, 19-20 November 2013 (pp. 1260-1268). Lampung

Attahmid, N.F.U., Saleh, R., Yusuf, M. (2019). Penerapan Teknologi Tepat Guna dan Diversifikasi Pangan pada UKM Olahan Ikan Bandeng di Desa Bulu Cindea Kecamatan Bungoro, Pangkep. Jurnal Pengabdian Pada Masyarakat, 4(4), 517-528. http://ppm.ejournal.id/index.php/pengabdian/article/view/237/125

Badan Pengawas Obat Dan Makanan. (2003). Pedoman Cara Produksi Pangan Yang Baik Untuk Industri Rumah Tangga (CPPB-IRT). Jakarta: Sampurno.

Dewi, A. R. (2018). Pendugaan Umur Simpan Gula Semut Aren Dengan Metode Arrhenius. (Skripsi). Institut Pertanian Bogor. Bogor. Indonesia

Evalia, N. A. Strategi Pengembangan Agroindustri Gula Semut Aren. (2015). Jurnal Manajemen \& Agribisnis, 2015; 12 (1), $57-67$. https://jurnal.ipb.ac.id/index.php/jmagr/article/view/10066/7875

Fahrizal, Nggandung, Y., \& Kartiwan. Optimasi Produksi Gula Cetak dan Gula Semut Lontar Terintegrasi Dengan Metode Linear Programming. Seminar Nasional Hasil Penelitian (SNHP)-Vii Lembaga Penelitian dan Pengabdian Kepada Masyarakat Universitas PGRI Semarang. 2017: 505 - 510. Joseph, G.H. \& Layuk, P. (2012). Pengolahan Gula Semut dari Aren. Buletin Palma, 13(1), 60 - 65. http://ejurnal.litbang.pertanian.go.id/index.php/palma/article/viewFile/5596/4771 


\section{Jcommdev}

JCOmmdev- JOURNAL OF COMMUNITY DEVELOPMENT \& EMPOWERMENT

E-ISSN : 2723-4398

Kurniawan, H., Bintoro, N., Karyadi, J.N.W. (2018). Pendugaan Umur Simpan Gula Semut dalam Kemasan Dengan Pendekatan Arrhenius. Jurnal IImiah Rekayasa Pertanian dan Biosistem, 6 (1), 93 - 99. http://jrpb.unram.ac.id/index.php/jrpb/article/view/68/60

Musita, N. (2019). Pengembangan Produk Gula Semut dari Aren dengan Penambahan Bubuk Rempah. Warta Industri Hasil Pertanian, 36(2), 106-113. http://ejournal.kemenperin.go.id/ihp/article/view/5212/pdf_47.

Ritonga, A. M., Masrukhi, Siswantoro. (2020). Pendugaan Umur Simpan Gula Kelapa Kristal Menggunakan Metode Akselerasi Berdasarkan Pendekatan Kadar Air Kritis. Jurnal Teknologi Pertanian, 21(1), 11-18. https://jtp.ub.ac.id/index.php/jtp/article/download/723/1030.

Septiyana, K.R., Adnand, M., Adriansyah, I., Nurkayanti, H., Kurniawan, H. (2019). Introduksi Alat Pengering bagi Pengerajin Gula Semut di Desa Kekait Kecamatan Gunung Sari Kabupaten Lombok Barat. Widyabhakti Jurnal IImiah Populer, 1(3), 83-90. https://widyabhakti.stikombali.ac.id/index.php/widyabhakti/article/view/111/59

Sushanti, G., \& Sirwanti. (2018). Laju Pengeringan Chips Mocaf Menggunakan Cabinet Dryer. Jurnal Galung Tropika, 7 (3), $229-235$.

https://jurnalpertanianumpar.com/index.php/jgt/article/view/372/pdf_45

Ummah, N., Purwanto, A. P., Suryani, A. (2016). Penentuan Konstanta Laju Pengeringan Bawang Merah (Allium ascalonicum L.) Iris Menggunakan Tunnel Dehydrator. Journal of Agro-based Industry, 33(2), 49-56. http://ejournal.kemenperin.go.id/ihp/article/download/3817/2936 